\title{
Oportunidades e desafios para lidar com as barreiras à adoção de práticas de green supply chain management: guidelines à luz de um estudo de múltiplos casos no Brasil
}

\author{
Opportunities and challenges for dealing with barriers to the adoption \\ of green supply chain management practices: guidelines based on \\ multiple-case studies in Brazil
}

\author{
Ana Beatriz Lopes de Sousa Jabbour ${ }^{1}$ \\ Caroline Lombardi de Souza ${ }^{1}$
}

\begin{abstract}
Resumo: Este artigo tem como objetivo apresentar e discutir como as principais empresas montadoras do setor de baterias automotivas instaladas no Brasil estão lidando com as barreiras à adoção de práticas de green supply chain management (GSCM). A partir dessas discussões, elencam-se oportunidade e desafios ao setor de baterias automotivas a fim de considerarem ações de GSCM. Foi realizado um estudo de múltiplos casos com as 5 principais empresas desse setor. Os fatores de destaque para as barreiras internas são "valores e fatores organizacionais" e "recursos humanos" e, para as externas, são "fornecedores" e "consumidores".
\end{abstract}

Palavras-chave: Green supply chain management. Barreiras. Oportunidades. Desafios. Empresas de baterias automotivas.

\begin{abstract}
This article aims to discuss how leading companies of the automotive battery industry installed in Brazil are dealing with barriers to the adoption of green supply chain management (GSCM) practices. From these discussions, we list the opportunities and challenges to the automotive battery sector in incorporating GSCM actions. We conducted a multiple-case study with the top five companies in this sector. The highlight factors are "organizational values" and "human resources" for internal barriers, and "suppliers" and "consumers" for external barriers.
\end{abstract}

Keywords: Green supply chain management. Barriers. Opportunities. Challenges. Automotive battery companies.

\section{Introdução}

A conscientização global a respeito das preocupações, proteção e tendências em relação ao meio ambiente para a conservação do planeta Terra está gerando pressões sobre as empresas (CHIEN \& SHIH, 2007). Nesse sentido, as organizações possuem o papel de amenizar seus impactos ambientais mediante ações em seus produtos e serviços (LEWIS \& GRETSAKIS, 2001; SARKIS, 1995, 2001). Uma forma estratégica de lidar com este contexto global é a partir da busca por melhores práticas de gerenciar aspectos de cadeias de suprimentos incorporando questões ambientais.

A incorporação de considerações ambientais na supply chain management (SCM) gera oportunidades de pesquisas para acadêmicos e profissionais da área (GOVINDAN \& CHENG, 2011). Tal abordagem é chamada de green supply chain management (GSCM), a qual integra nas operações fabris questões ambientais com o propósito de reduzir os custos operacionais do ciclo de vida do produto e de reduzir a geração de resíduos e emissões de poluentes, utilizando os recursos de maneira mais sustentável (BEAMON, 1999; THUN \& MÜLLER, 2010).

No entanto, organizações que pretenderem incluir abordagens "verdes" em sua SCM encontrarão barreiras e motivadores, que dificultarão ou conduzirão a realização de mudanças e melhorias no desempenho ambiental organizacional (WALKER et al., 2008).

Os estudos mais citados sobre barreiras à adoção de práticas de GSCM, segundo pesquisa na base de dados SCOPUS (2013) tangenciam os

\footnotetext{
${ }^{1}$ Departamento de Engenharia de Produção, Faculdade de Engenharia, Universidade Estadual Paulista - UNESP, Av. Engenheiro Luiz Edmundo Corrijo Coube, 14-01, Vargem Limpa, CEP 17033-360, Bauru, SP, Brasil, e-mail: abjabbour@feb.unesp.br; clombardi.souza@hotmail.com
}

Recebido em Ago. 3, 2013 - Aceito em Jan. 15, 2015

Suporte financeiro: Agradecemos ao Conselho Nacional de Desenvolvimento Científico e Tecnológico (CNPq) pelo suporte ao desenvolvimento desta pesquisa (Processo 304225/2013-4) e a Coordenação de Aperfeiçoamento de Pessoal de Nível Superior (Capes) pela concessão de bolsa de mestrado. 
temas: (a) identificação de motivações e barreiras para integrar práticas ambientais na cadeia de suprimentos (WALKER et al., 2008; THUN \& MULLER, 2010) e (b) classificação das barreiras à adoção de GSCM a partir de métodos matemáticos (MUDGAL et al., 2010; LUTHRA et al., 2011; MATHIYAZHAGAN et al., 2013; MUDULI et al., 2013). Dentre esses, o artigo que propõe formas de superar as barreiras é o de Luthra et al. (2011). No Brasil, ao se fazer buscas no Scielo, o tema de GSCM tem sido abordado majoritariamente com o enfoque em estudos bibliométricos (BRITO \& BERARDI, 2010; PEREIRA et al., 2011; DIAS et al., 2012). Portanto, vislumbra-se como oportunidade de pesquisa responder à seguinte questão: como empresas do setor de baterias automotivas estão lidando com as barreiras à adoção de práticas de GSCM? Esta pergunta ainda não tem sido respondida no âmbito das pesquisas brasileiras. No âmbito internacional, o enfoque em geral é listar as barreiras e hierarquizá-las, e não propriamente apresentar como as empresas lidam com elas.

Em virtude disso, este artigo possui como objetivo central apresentar e discutir como as principais empresas montadoras do setor de baterias automotivas instaladas no Brasil estão lidando com as barreiras à adoção de práticas de GSCM. Por meio da técnica de estudo de múltiplos casos, esta pesquisa estudou as cinco principais empresas produtoras de baterias automotivas instaladas no Brasil, a fim de também elencar oportunidades e desafios ao setor com a finalidade de incorporar ações de GSCM.

O setor de baterias automotivas está intrinsecamente vinculado ao setor automotivo, o principal vetor das principais economias do mundo. Além do mais, aquele setor possui considerável potencial de impactos ambientais em função do manuseio do chumbo-ácido, seu principal insumo.

Esse artigo está dividido em cinco seções dentre as quais, tem-se a seção 2, Revisão de literatura, que apresenta os principais fundamentos conceituais sobre GSCM e barreiras à GSCM; a seção 3, Método de Pesquisa, que caracteriza as empresas estudadas e apresenta os procedimentos de coleta e análise dos dados; a seção 4, Resultados e Discussões, que apresenta os principais resultados da pesquisa e elenca as oportunidades e desafios ao setor; e, na seção 5, estão as Conclusões da pesquisa.

\section{Revisão de literatura}

\subsection{Green Supply Chain Management (GSCM)}

Sarkis et al. (2011) definem GSCM como sendo a integração das preocupações ambientais nas práticas organizacionais da gestão da cadeia de suprimentos.
Zhu et al. (2008a, 2008c, 2008d) complementam que esta integração visa minimizar os impactos ambientais e sociais de um produto ou serviço, variando desde compras mais sustentáveis até a integração de todo o fluxo da cadeia de suprimentos, do fornecedor ao cliente.

As práticas de GSCM são definidas como ações realizadas na cadeia de suprimentos que pertencem aos níveis estratégico, tático e operacional por meio do relacionamento entre parceiros ao longo da cadeia (AZEVEDO et al., 2011). Zhu et al. (2008d) validaram estatisticamente as práticas de GSCM, portanto, para este artigo, elas são utilizadas como referência.

- Gestão ambiental interna. Essencial para a adoção das práticas de GSCM, necessitando do apoio e do comprometimento da alta e média gerência na certificação ISO 14001 e no estabelecimento de um Sistema de Gestão Ambiental (ZHU et al., 2008a, 2008b; 2008d; ZHU \& SARKIS, 2006).

- Compras verdes. Lee (2008) afirma que a GSCM é um programa que destaca a transferência e a disseminação da gestão ambiental em toda a cadeia de suprimentos por meio das relações de compras e com fornecedores. As compras verdes incluem a seleção de fornecedores para a compra de itens que possuem atributos ambientais desejáveis tais como reuso, reciclabilidade e ausência de substâncias perigosas (CARTER \& CARTER, 1998; MIN \& GALLE, 2001; PREUSS, 2001; HERVANI et al., 2005; WALTON et al., 1998).

- Cooperação com clientes. Compartilhamento do risco ambiental e integração do fluxo reverso de materiais e informações (DÜES et al., 2012).

- Ecodesign. Visa os aspectos de ecoeficiência ou design para o ambiente, inclui atividades que objetivam a minimização dos impactos dos produtos durante seu ciclo de vida (SARKIS, 1998; WALTON et al., 1998; HERVANI et al., 2005).

- Recuperação de investimento. Seu objetivo é gerenciar o estoque ao vender o excesso de inventário, sucata, equipamentos e materiais usados (ZHU et al. 2008c, 2008d; LIU et al., 2011).

Posteriormente, Srivastava (2007) e Sarkis et al. (2011) adicionaram a logística reversa como uma das práticas de GSCM. Portanto, também foi considerada esta prática.

- Logística reversa. É caracterizada como uma atividade de gestão de materiais necessária para realizar a recuperação do produto, 
movimentação de materiais e redução na fonte (CORBETT \& KLASSEN, 2006; FORTES, 2009).

\subsection{Barreiras à adoção das práticas de GSCM}

Para Perron (2005), barreiras são os elementos que impedem a adoção de iniciativas ambientais nas organizações, e as classifica em quatro categorias:

- Barreiras atitudinais ou perceptivas: falta de atitudes e comportamentos da alta gerência para com as questões ambientais, por exemplo, a resistência da gerência à mudança.

- Barreiras de informação: impedem a acessibilidade da informação e dificultam a comunicação, por exemplo, a falta de compreensão da legislação ambiental e do impacto ambiental das operações na organização.

- Barreiras de recursos: ausência de algum tipo de recurso para a implantação da gestão ambiental, por exemplo, recursos financeiros e recursos humanos.

- Barreiras técnicas: impedem a acessibilidade e a ascensão do conhecimento, por exemplo, a ausência de novas tecnologias, materiais ou experiência.

Os Quadros 1 e 2 resumem os principais fatores internos e externos relativos as barreiras à adoção de práticas de GSCM.

A seguir, é apresentada uma breve discussão dos artigos mais citados sobre as barreiras à adoção das práticas de GSCM, utilizando as palavras-chave "green supply chain management" e "barriers" na base de dados Scopus (tal busca foi elaborada em julho de 2013).

Walker et al. (2008) concluíram que há barreiras tanto internas (custos e falta de legitimidade) quanto externas (regulamentação, falta de comprometimento dos fornecedores e barreiras específicas à indústria) e que, se as barreiras internas forem mais numerosas, superá-las é uma vantagem em relação às barreiras externas.

Ferrer-Balas et al. (2008) destacam formas como uma Universidade Espanhola superou barreiras à disseminação da prática de compras verdes entre os elos de sua cadeia. As principais barreiras identificadas são externas, tais como fornecedor e consumidor.

Thun \& Muller (2010) identificaram que as principais barreiras internas na amostra estudada (indústria automotiva alemã) são: alterações necessárias por exigências ambientais, falta de aceitação dentro da empresa e aumento dos custos relacionados. Assim, os esforços devem ser realizados no intuito de mudar a atitude em relação à GSCM e para suavizar mal-entendidos. Quanto às barreiras externas, destacam-se os diferentes atos e regulamentos ambientais com que as empresas que atuam globalmente são confrontadas. Os autores destacam a importância da parceria na cadeia de suprimentos para superar essa barreira.

Luthra et al. (2011) identificaram, a partir da metodologia ISM (Interpretative Strutural Modeling), as principais barreiras à adoção de práticas de GSCM no contexto do setor automotivo indiano, que são: concorrência, custos e cliente. E eles destacam que, a falta de suporte do Governo, é o um impulsionador para a geração dessas barreiras.

Quadro 1. Fatores internos.

\begin{tabular}{|l|l|l|}
\hline \multicolumn{1}{|c|}{ Fatores Internos } & \multicolumn{1}{|c|}{ Barreiras (autores) } & \multicolumn{1}{c|}{ Definição } \\
\hline $\begin{array}{l}\text { Valores e fatores } \\
\text { organizacionais }\end{array}$ & $\begin{array}{l}\text { Luthra et al. (2011) } \\
\text { Walker et al. (2008) } \\
\text { Ageron et al. (2012) } \\
\text { Giunipero et al. (2012) }\end{array}$ & $\begin{array}{l}\text { São o comprometimento e o apoio dos membros } \\
\text { da alta cúpula administrativa e dos funcionários. } \\
\text { Abrangem questões culturais, atendimento de } \\
\text { objetivos e gestão do conhecimento. }\end{array}$ \\
\hline Recursos humanos & $\begin{array}{l}\text { Luthra et al. (2011) } \\
\text { Wolfslehner \& Vacik (2008) }\end{array}$ & Referem-se ao capital humano da empresa. \\
\hline Custos & $\begin{array}{l}\text { Pajunen et al. (2012) } \\
\text { Walker et al. (2008) } \\
\text { Luthra et al. (2011) } \\
\text { Zhang et al. (2009) } \\
\text { Giunipero et al. (2012) }\end{array}$ & $\begin{array}{l}\text { Fator financeiro que promove ou inibe a realização } \\
\text { de mudanças e melhorias nos processos e produtos } \\
\text { organizacionais. }\end{array}$ \\
\hline $\begin{array}{l}\text { Disponibilidade de } \\
\text { recursos }\end{array}$ & $\begin{array}{l}\text { Adriana (2009) } \\
\text { Zhu \& Geng (2013) } \\
\text { Luthra et al. (2011) }\end{array}$ & $\begin{array}{l}\text { Refere-se à disponibilidade de ativos, capacidades } \\
\text { de processos organizacionais, informações e } \\
\text { conhecimento, recursos financeiros e de tempo. } \\
\text { Oferece capacidades únicas para gerenciar mudanças e } \\
\text { identificar oportunidades. }\end{array}$ \\
\hline
\end{tabular}

Fonte: Elaborado pelos autores (2013). 
Quadro 2. Fatores externos.

\begin{tabular}{|c|c|c|}
\hline Fatores Externos & Barreiras (autores) & Definição \\
\hline $\begin{array}{l}\text { Regulamentações } \\
\text { governamentais e } \\
\text { legislações }\end{array}$ & $\begin{array}{l}\text { Bjorklund (2011) } \\
\text { Pajunen et al. (2012) } \\
\text { Tsoulfas \& Pappis (2008) } \\
\text { Luthra et al. (2011) } \\
\text { Walker et al. (2008) } \\
\text { Giunipero et al. (2012) }\end{array}$ & $\begin{array}{l}\text { Referem-se aos órgãos regulamentadores, que } \\
\text { fornecem leis e normas de comportamento para } \\
\text { empresas, forçando-as à adoção de ações. }\end{array}$ \\
\hline Consumidores & $\begin{array}{l}\text { Luthra et al. (2011) } \\
\text { Simpson (2012) }\end{array}$ & $\begin{array}{l}\text { Desejam produtos e serviços que satisfaçam cada vez } \\
\text { mais suas necessidades e anseios, provocam pressões } \\
\text { nas empresas exercendo influência sobre o mercado no } \\
\text { qual a empresa atua. }\end{array}$ \\
\hline Concorrência & $\begin{array}{l}\text { Luthra et al. (2011) } \\
\text { Bjorklund (2011) }\end{array}$ & $\begin{array}{l}\text { Desafia as empresas a manterem-se competitivas no } \\
\text { mercado e altamente produtivas. }\end{array}$ \\
\hline Fornecedores & $\begin{array}{l}\text { Luthra et al. (2011) } \\
\text { Bjorklund (2011) }\end{array}$ & $\begin{array}{l}\text { Fabricantes de componentes e transformadores de } \\
\text { matéria-prima. }\end{array}$ \\
\hline $\begin{array}{l}\text { Sociedade e imagem } \\
\text { corporativa }\end{array}$ & Walker et al. (2008) & $\begin{array}{l}\text { Os grupos de interesse são sensíveis e influenciados } \\
\text { por qualquer comportamento ou atitude da empresa; a } \\
\text { imagem da empresa interfere nas escolhas dos clientes } \\
\text { finais. }\end{array}$ \\
\hline Tecnologia & $\begin{array}{l}\text { Luthra et al. (2011) } \\
\text { Yongan \& Menghan (2011) }\end{array}$ & $\begin{array}{l}\text { É um tipo de conhecimento que a empresa possui } \\
\text { a fim de obter maiores habilidades para implantar } \\
\text { inovações e encorajar novas ideias. }\end{array}$ \\
\hline
\end{tabular}

Fonte: Elaborado pelos autores (2013).

Mathiyazhagan et al. (2013) hierarquizam 26 barreiras à adoção de GSCM a partir da metodologia ISM e constataram que, no contexto do setor automotivo indiano, o fator-chave a ser trabalhado para melhorar as ações de GSCM é a consciência ambiental dos fornecedores.

E, Muduli et al. (2013), a partir de um estudo em empresas de grande e pequeno porte do segmento de mineração, e fazendo uso de modelagem matemática, detectaram que a restrição de capacidade é uma barreira relevante para as pequenas empresas, enquanto que para as grandes, a barreira mais relevante é o aspecto legal.

Segundo os estudos destacados, tem-se que a barreira interna mais identificada nos estudos anteriores é custos e as barreiras externas são regulamentação e fornecedores.

\section{Método de pesquisa}

Esta pesquisa é caracterizada como qualitativa e exploratória e fez-se uso da técnica de estudo de múltiplos casos. A seleção das empresas para compor o estudo foi em função do critério relevância no setor, uma vez que a amostra corresponde às cinco principais empresas produtoras de baterias automotivas instaladas no Brasil (CASTRO et al., 2013), sendo quatro nacionais e uma multinacional. Assim, elas podem representar o setor de baterias automotivas de forma a gerar lições para o setor como um todo.
O roteiro de entrevistas foi constituído por três seções: (1) caracterização da empresa, esta seção foi elaborada para obter informações de cada empresa sobre os principais produtos fornecidos, o tipo de mercado que abastece e as certificações que possuem; (2) adoção de práticas de GSCM, foi questionado em cada empresa se as práticas gestão ambiental interna, compras verdes, cooperação com cliente, ecodesign, recuperação de investimento e logística reversa são consideradas por elas, se sim, que dessem alguns exemplos de como cada prática estava sendo adotada; e (3) barreiras à adoção de práticas de GSCM, nessa seção, com base nos Quadros 1 e 2 do referencial teórico do artigo, elencaram-se os fatores internos e externos e perguntou-se se aqueles fatores eram barreiras atuais para a adoção das práticas de GSCM nas empresas, e, se sim, que comentassem como a empresa tem lidado para superá-las.

A coleta de dados foi feita mediante entrevista com o responsável pela área ambiental de cada empresa, tendo como primeiros contatos o meio telefônico e e-mail. Juntamente com a entrevista foram consideradas outras evidências, realizando-se visitação in loco no chão de fábrica e na unidade de reciclagem; observação de painéis informativos (políticas organizacionais, ambientais e de segurança) e solicitação de outros materiais que complementassem a pesquisa. Em média, cada entrevista durou em torno de 3 horas. O Quadro 3 resume as fontes de dados obtidos. 
Quadro 3. Resumo das fontes de dados obtidas.

\begin{tabular}{|c|c|c|c|c|c|c|}
\hline Empresa & Data da Visita & $\begin{array}{c}\text { Primeiro } \\
\text { contato }\end{array}$ & $\begin{array}{c}\text { Cargo do } \\
\text { Entrevistado }\end{array}$ & $\begin{array}{c}\text { Departamento } \\
\text { do } \\
\text { entrevistado }\end{array}$ & $\begin{array}{c}\text { Aplicação } \\
\text { do roteiro de } \\
\text { entrevista }\end{array}$ & $\begin{array}{c}\text { Materiais extras } \\
\text { disponibilizados }\end{array}$ \\
\hline Empresa A & Fevereiro/2013 & E-mail & Coordenador & $\begin{array}{l}\text { Departamento } \\
\text { de meio } \\
\text { ambiente }\end{array}$ & $\begin{array}{l}\text { Visita in loco } \\
\text { (observação da } \\
\text { planta industrial) }\end{array}$ & $\begin{array}{l}\text { Artigo científico } \\
\text { publicado pelo } \\
\text { entrevistado e uma } \\
\text { dissertação de outro } \\
\text { autor, relacionados } \\
\text { à Empresa A e } \\
\text { visualização do site }\end{array}$ \\
\hline Empresa B & $\begin{array}{l}\text { Março/ } \\
2013\end{array}$ & $\begin{array}{l}\text { E-mail e } \\
\text { telefone }\end{array}$ & $\begin{array}{l}\text { Supervisor } \\
\text { químico e } \\
\text { ambiental }\end{array}$ & $\begin{array}{l}\text { Departamento } \\
\text { químico e } \\
\text { ambiental }\end{array}$ & $\begin{array}{l}\text { Prévia do roteiro } \\
\text { por } e \text {-mail e visita } \\
\text { in loco } \\
\text { (observação das } \\
\text { plantas industrial } \\
\text { e de reciclagem) }\end{array}$ & $\begin{array}{l}\text { Visualização do site } \\
\text { e observação de } \\
\text { painéis informativos } \\
\text { (políticas } \\
\text { organizacionais, } \\
\text { ambientais e de } \\
\text { segurança) }\end{array}$ \\
\hline Empresa $C$ & $\begin{array}{l}\text { Março/ } \\
2013\end{array}$ & $\begin{array}{l}\text { E-mail e } \\
\text { telefone }\end{array}$ & $\begin{array}{l}\text { Encarregado de } \\
\text { meio ambiente }\end{array}$ & $\begin{array}{l}\text { Laboratório } \\
\text { ambiental }\end{array}$ & $\begin{array}{l}\text { Prévia do roteiro } \\
\text { por } e \text {-mail e visita } \\
\text { in loco } \\
\text { (observação das } \\
\text { plantas industrial } \\
\text { e de reciclagem) }\end{array}$ & $\begin{array}{l}\text { Visualização do site } \\
\text { e observação de } \\
\text { painéis informativos } \\
\text { (políticas } \\
\text { organizacionais, } \\
\text { ambientais e de } \\
\text { segurança) }\end{array}$ \\
\hline Empresa $D$ & $\begin{array}{l}\text { Abril/ } \\
2013\end{array}$ & $\begin{array}{l}\text { E-mail e } \\
\text { telefone }\end{array}$ & Coordenador & $\begin{array}{l}\text { Departamento } \\
\text { de meio } \\
\text { ambiente }\end{array}$ & $\begin{array}{l}\text { Prévia do roteiro } \\
\text { por } e \text {-mail e visita } \\
\text { in loco } \\
\text { (observação da } \\
\text { planta industrial) }\end{array}$ & $\begin{array}{l}\text { Visualização do site } \\
\text { e disponibilização } \\
\text { da Regulamentação } \\
\text { CONAMA }\end{array}$ \\
\hline Empresa $E$ & $\begin{array}{l}\text { Abril/ } \\
2013\end{array}$ & $\begin{array}{l}\text { E-mail e } \\
\text { telefone }\end{array}$ & Gerente & $\begin{array}{l}\text { Departamento } \\
\text { de desenvolvi- } \\
\text { mento de } \\
\text { fornecedores }\end{array}$ & $\begin{array}{l}\text { Prévia do roteiro } \\
\text { por } e \text {-mail } \\
\text { e entrevista } \\
\text { por vídeo e } \\
\text { teleconferência }\end{array}$ & Visualização do site \\
\hline
\end{tabular}

Fonte: Elaborado pelos autores (2013).

A análise dos dados seguiu os procedimentos: elaboração de um relatório das respostas obtidas em cada empresa, conforme as palavras dos entrevistados, uma vez que não foi autorizada a gravação das entrevistas. A partir desse relatório, montaram-se quadros (Quadros 4 a 13) sintetizando e comparando os principais argumentos mencionados pelos entrevistados quanto às barreiras enfrentadas pelas empresas, com a forma como lidam com cada uma delas, à adoção de práticas de GSCM, para poder identificar algum padrão de comportamento entre os casos. Por fim, procurou-se destacar eventuais alinhamentos ou desalinhamentos entre as evidências destacadas na revisão de literatura com as evidências dos Quadros elaborados, para gerar discussões e destacar as contribuições do estudo de múltiplos casos. O Quadro 14 apresenta algumas características das empresas estudadas.

\section{Resultados e discussões}

\subsection{Práticas de GSCM}

As práticas de GSCM mais adotadas pelas empresas estudadas são a gestão ambiental interna e logística reversa. As empresas estudadas são unânimes quanto à adoção da gestão ambiental interna. Segundo os entrevistados, as organizações possuem a necessidade de um líder para apoiar, organizar e direcionar as atividades de melhoria ambiental, e, portanto, que haja uma área funcional dedicada à gestão ambiental para acompanhar os requisitos legais, dos clientes, dos fornecedores, envolver os colaboradores para as melhorias ambientais internas e implantar certificações para melhoria contínua de seus produtos e processos.

A logística reversa também é unânime. A adoção pelas empresas é executada pela própria empresa ou por empresa terceirizada. As empresas têm 
diminuído o descarte de materiais nocivos e reduzido seus custos de produção, pois conseguem recuperar em média $90 \%$ da bateria usada. A logística reversa neste setor possui um papel econômico e ambiental.

\subsection{Barreiras internas}

O fator "valores e fatores organizacionais" é uma barreira presente em 4 das 5 empresas estudadas. As empresas B, C, D e E apresentam diferentes raízes para a existência de barreiras no que concerne a esse fator, como, dificuldades de cumprir a legislação (empresa B); resistência dos colaboradores à mudança em processos (empresa C); heterogeneidade na escolaridade e no perfil dos colaboradores (empresa D); e centralização de decisões e indisponibilidade de recursos humanos (empresa E). As principais formas de lidar com este fator são treinando e conscientizando os funcionários (empresas $\mathrm{C}$ e D) e tendo o apoio da alta administração (empresa E).

De uma forma sintética e agrupando os principais resultados, pode-se afirmar que os "valores e fatores organizacionais" atuam como barreira (Quadro 4) quando há necessidade de mudança de processos, falta de habilidades técnicas e pessoais dos colaboradores, e indisponibilidade de pessoas. O que vai ao encontro dos resultados de Thun \& Muller (2010). Nesse sentido, é importante dar atenção a aspectos de gestão de recursos humanos para minimizar barreiras à GSCM.

O fator "recursos humanos" é considerado uma barreira para todas as empresas estudadas. Houve unanimidade entre as empresas A, B e C ao afirmar que a resistência dos colaboradores à mudança na forma como executar novos procedimentos de trabalho é uma barreira marcante no que tange a "recursos humanos". Para a empresa D, aspectos como inabilidade técnica e pessoal é uma dificuldade para a adoção de práticas de GSCM; e para a empresa E, a maior dificuldade é recrutar pessoas qualificadas. As formas como as empresas têm lidado com esse fator são treinando e conscientizando quanto à necessidade da mudança (empresas A, B e C) e incentivando os funcionários a partir de premiações e bonificações (empresas D e E).

Para o "fator recursos humanos" (Quadro 5), as barreiras de destaque são a resistência dos funcionários às mudanças, confirmando os resultados de Thun \& Muller (2010) e reforçando o que foi discutido para o fator "valores e fatores organizacionais".

Todas as empresas estudadas consideram o fator "custo" como uma barreira à adoção de práticas de GSCM. Em geral, os entrevistados afirmaram que esse fator se torna uma barreira quando não é possível mensurar o investimento e o seu retorno (empresas A, B e C). Para as empresas D e E, esse fator é uma barreira quando o custo é muito elevado por circunstâncias regulatórias, como pagamento de auditorias. A forma como as empresas têm lidado com este fator é a partir da realização de investimentos necessários sem afetar os aspectos de competitividade.

Os custos são vistos de forma intrínseca ao processo de adoção das práticas de GSCM (Quadro 6) para a maioria das empresas estudadas, entretanto, atuam como barreiras quando são altos e não conseguem ser mensurados. Os custos tinham sido destacados como barreiras internas por Walker et al. (2008), Thun \& Muller (2010), e Luthra et al. (2011).

Quadro 4. Análise cruzada do fator "Valores e fatores organizacionais".

\begin{tabular}{|l|l|l|}
\hline $\begin{array}{c}\text { Valores } \text { e fatores } \\
\text { organizacionais }\end{array}$ & \multicolumn{1}{|c|}{ Barreira identificada } & \multicolumn{1}{c|}{ Como a empresa lida } \\
\hline Empresa A & A empresa não relatou nenhuma barreira & \multicolumn{1}{|c|}{ - } \\
\hline Empresa B & $\begin{array}{l}\text { Quando a alta gerência não consegue cumprir } \\
\text { a legislação. }\end{array}$ & $\begin{array}{l}\text { Toma as ações necessárias para atender às } \\
\text { várias CONAMAS. A empresa atua sob as } \\
\text { práticas preventivas e proativas da poluição. }\end{array}$ \\
\hline Empresa $C$ & $\begin{array}{l}\text { Quando há necessidade de mudanças em } \\
\text { processos já existentes e nos novos. }\end{array}$ & $\begin{array}{l}\text { Lidam com muita persistência, mostrando } \\
\text { os benefícios e conscientizando os } \\
\text { funcionários por meio de treinamento. }\end{array}$ \\
\hline Empresa $D$ & $\begin{array}{l}\text { Quando a heterogeneidade das pessoas } \\
\text { atrapalha o cumprimento das metas e } \\
\text { objetivos. }\end{array}$ & $\begin{array}{l}\text { A empresa procura sempre treinar e } \\
\text { minimizar as diferenças. Quando o } \\
\text { funcionário persiste no erro e não colabora } \\
\text { é demitido. }\end{array}$ \\
\hline Empresa $E$ & $\begin{array}{l}\text { Quando a administração era centralizada } \\
\text { em uma pessoa só, sendo insuficientes suas } \\
\text { operações. }\end{array}$ & $\begin{array}{l}\text { Tendo a conscientização da diretoria da } \\
\text { necessidade de aumentar seu quadro de } \\
\text { pessoal para cuidar melhor das questões } \\
\text { ambientais e corrigir metas. }\end{array}$ \\
\hline
\end{tabular}

Fonte: Coleta de dados (2013). 
Quadro 5. Análise cruzada do fator "Recursos humanos".

\begin{tabular}{|c|c|c|}
\hline $\begin{array}{l}\text { Recursos } \\
\text { Humanos }\end{array}$ & Barreira identificada & Como a empresa lida \\
\hline Empresa A & $\begin{array}{l}\text { Os funcionários mais antigos eram resistentes } \\
\text { às mudanças e padronização da produção, } \\
\text { pois cada um tinha seu próprio modo de } \\
\text { trabalhar. }\end{array}$ & $\begin{array}{l}\text { A empresa tratou estes casos com vários } \\
\text { treinamentos e conscientização. }\end{array}$ \\
\hline Empresa B & $\begin{array}{l}\text { Há algumas restrições a aceitar certas } \\
\text { mudanças do trabalho. }\end{array}$ & $\begin{array}{l}\text { Procura investir em conscientização e treinamentos, } \\
\text { além de reverter a renda das embalagens de papelão } \\
\text { e plásticos em brindes e premiações aos funcionários. }\end{array}$ \\
\hline Empresa $C$ & $\begin{array}{l}\text { Resistência dos colaboradores de chão de } \\
\text { fábrica e de alguns gestores, geralmente os } \\
\text { que estão há mais tempo na empresa. }\end{array}$ & Investe em conscientização e treinamentos. \\
\hline Empresa D & $\begin{array}{l}\text { Quando a heterogeneidade das pessoas } \\
\text { atrapalha o cumprimento das metas e } \\
\text { objetivos. }\end{array}$ & $\begin{array}{l}\text { A empresa procura sempre treinar e minimizar as } \\
\text { diferenças. Quando o funcionário persiste no erro e } \\
\text { não colabora é demitido. }\end{array}$ \\
\hline Empresa E & $\begin{array}{l}\text { Quando há a dificuldade de contratar pessoas } \\
\text { qualificadas para o trabalho. }\end{array}$ & $\begin{array}{l}\text { Incentivos para o pessoal na forma de bonificações, } \\
\text { utilizando o lucro de tudo que é reciclado (papel, } \\
\text { plástico, entre outros) para premiações dos } \\
\text { funcionários e ajudas de custo como o pagamento de } \\
\text { aluguel. }\end{array}$ \\
\hline
\end{tabular}

Fonte: Coleta de dados (2013).

Quadro 6. Análise cruzada do fator "Custos".

\begin{tabular}{|l|l|l|}
\hline \multicolumn{1}{|c|}{ Custos } & \multicolumn{1}{|c|}{ Barreira identificada } & \multicolumn{1}{c|}{ Como a empresa lida } \\
\hline Empresa $A$ & $\begin{array}{l}\text { Quando não se consegue mensurar o } \\
\text { investimento. }\end{array}$ & $\begin{array}{l}\text { Elaboram estratégias, as quais não puderam ser } \\
\text { divulgadas, para que a empresa possa recuperar } \\
\text { seu equilíbrio financeiro. }\end{array}$ \\
\hline Empresa $B$ & $\begin{array}{l}\text { Quando não se consegue mensurar o } \\
\text { investimento. } \\
\text { Elaboram estratégias, as quais não puderam ser } \\
\text { divulgadas, para que a empresa possa recuperar } \\
\text { seu equilíbrio financeiro. }\end{array}$ \\
\hline Empresa $D$ & $\begin{array}{l}\text { Se não acertar o custo correto torna-se uma } \\
\text { barreira. }\end{array}$ & $\begin{array}{l}\text { É uma empresa que entende a necessidade de } \\
\text { fazer sua parte para com o meio ambiente, então } \\
\text { procura sempre trabalhar em prol dele. }\end{array}$ \\
\hline $\begin{array}{l}\text { Quando é elevado, o Governo exige o } \\
\text { pagamento de altas taxas, auditorias e } \\
\text { implantação de certificações. Por exemplo, } \\
\text { a empresa tem um alto custo para reciclar a } \\
\text { água utilizada no processo de fabricação de } \\
\text { baterias e isso faz com que a empresa desanime } \\
\text { em implantar algo maior do que todos estão } \\
\text { fazendo, já que sua política é sempre pautada } \\
\text { pelo custo. }\end{array}$ & $\begin{array}{l}\text { A empresa faz o necessário para que possa } \\
\text { permanecer no mercado. }\end{array}$ \\
\hline Empresa $E$ & $\begin{array}{l}\text { Quando é alto, com treinamentos e auditorias. } \\
\text { Emarte e que os custos são necessários. }\end{array}$ \\
\hline
\end{tabular}

Fonte: Coleta de dados (2013).

O fator "disponibilidade de recursos" foi considerado uma barreira para 4 das 5 empresas estudadas. As respostas foram difusas entre os entrevistados. Por exemplo, para a empresa C, esse fator é uma barreira quando o custo não é bem calculado; e para a empresa E, é uma barreira quando não há disponibilidade de recursos humanos para lidar com a demanda ambiental da empresa. As empresas têm tentando lidar com este fator fazendo investimentos necessários sem afetar os aspectos de competitividade.

Observando de uma forma integrada, o fator "disponibilidade de recursos" (Quadro 7) é uma barreira quando não há apoio da alta administração em investir em melhorias ambientais ou o custo não é justificado. Muduli et al. (2013) destacaram que a restrição de recursos é uma barreira, principalmente, para pequenas empresas. Nesta 
Quadro 7. Análise cruzada do fator "Disponibilidade de recursos".

\begin{tabular}{|c|c|c|}
\hline $\begin{array}{c}\text { Disponibilidade de } \\
\text { Recursos }\end{array}$ & Barreira identificada & Como a empresa lida \\
\hline Empresa A & Não enfrentou barreiras. & - \\
\hline Empresa $B$ & Quando há falta de recursos. & $\begin{array}{l}\text { Os recursos são disponibilizados e } \\
\text { aprovados mediante a justificativa. } \\
\text { Caso a empresa não possa atender de } \\
\text { imediato é postergado, mas ela entende as } \\
\text { necessidades. }\end{array}$ \\
\hline Empresa C & $\begin{array}{l}\text { Se não acertar o custo correto torna-se uma } \\
\text { barreira. }\end{array}$ & $\begin{array}{l}\text { É uma empresa que entende a necessidade } \\
\text { de fazer sua parte para com o meio } \\
\text { ambiente, então procura sempre trabalhar } \\
\text { em prol dele. }\end{array}$ \\
\hline Empresa D & $\begin{array}{l}\text { Quando por falta de recursos, ordens de } \\
\text { compras para adequação ambiental de } \\
\text { processos não é autorizada. }\end{array}$ & $\begin{array}{l}\text { A empresa entende as necessidades, mas } \\
\text { tudo tem que ser justificado. }\end{array}$ \\
\hline Empresa E & $\begin{array}{l}\text { Quando existia somente um único diretor, } \\
\text { ficava tudo centralizado em seu poder e ele } \\
\text { não conseguia dar conta de disponibilizar } \\
\text { muitos recursos e nem gerenciar melhor o } \\
\text { setor ambiental. }\end{array}$ & $\begin{array}{l}\text { Além de criar um departamento voltado } \\
\text { para cuidar da gestão ambiental interna da } \\
\text { empresa, contratou um líder para cuidar } \\
\text { exclusivamente da área. }\end{array}$ \\
\hline
\end{tabular}

Fonte: Coleta de dados (2013).

pesquisa, estudaram-se médias e grandes empresas, portanto, o fator "disponibilidade de recursos" também pode afetar empresas de maior porte.

Considerando-se as formas como as empresas estudadas lidam com as barreiras internas, e considerando a homogeneidade entre as respostas, tem-se a percepção de que os fatores "valores e fatores organizacionais" e os "recursos humanos" são as barreiras de maior destaque e impacto para elas. O fator "custo" foi bastante destacado pelas empresas, mas os entrevistados consideram que ele é algo inerente aos negócios e não especificamente à adoção de práticas de GSCM.

\subsection{Barreiras externas}

A respeito do fator "regulamentações e legislações governamentais" (Quadro 8), todas as empresas julgaram este fator como uma barreira crítica, por elas gerarem custos adicionais, ou por burocratizar certas atividades da empresa, por exemplo, licenças de transporte, de acordo com o entrevistado da Empresa D. Conforme a Empresa A, as legislações "não beneficiam em nada na prática" e a Empresa $\mathrm{C}$ alega que o "governo somente exige e não proporciona nenhum benefício". A literatura consultada destaca que, realmente, este fator é fonte geradora de barreiras (WALKER et al., 2008; THUN \& MULLER, 2010; LUTHRA et al., 2011; MUDULI et al., 2013). As empresas têm lidado de duas formas com esta barreira: (a) acompanhando a legislação pertinente a ser cumprida por meio de um site pago e (b) cumprindo as regulamentações impostas, pois, segundo o relato das Empresas A, B e C, "não possuem flexibilidade nem brechas".

Para 4 das 5 empresas estudadas, o fator “consumidores" é uma barreira (Quadro 9) à adoção de práticas de GSCM. Para as empresas B, $\mathrm{C}$ e E, quando o cliente não efetua a devolução da bateria em um centro autorizado após o fim de sua vida útil, inviabiliza a prática de logística reversa, uma vez que é possível reutilizar o chumbo das baterias descartadas. Em geral, as empresas lidam com este fator tentando conscientizar os clientes e tentando gerar benefícios pela devolução da bateria descartada.

Ferrer-Balas et al. (2008) e Luthra et al. (2011) destacaram que os consumidores são fatores barreiras, principalmente quando eles não reconhecem e não valorizam as ações ambientais das empresas, o que também foi detectado nesta pesquisa, uma vez que a cooperação do cliente para a devolução das baterias pós-consumo nem sempre ocorre.

Todas as empresas destacaram o fator "concorrência" (Quadro 10) como uma barreira à adoção de práticas de GSCM. Segundo os entrevistados, o fator concorrência inibe maiores ações em prol de gestão ambiental, quando há no mercado empresas com estratégias de competir com menor preço que elas e com menores investimentos em adequação ambiental do produto (empresas A, B, $\mathrm{C}$ e D). As empresas lidam com este fator de maneira a não reduzir seus investimentos no cumprimento dos requisitos legais ambientais, mas, ao mesmo tempo, tentado adotar estratégias competitivas que as façam ter um preço competitivo. Luthra et al. (2011) já haviam destacado este fator como uma barreira no 
Quadro 8. Análise cruzada do fator "Regulamentações e legislações governamentais".

\begin{tabular}{|c|c|c|}
\hline $\begin{array}{c}\text { Regulamentações } \\
\text { e legislações } \\
\text { governamentais }\end{array}$ & Barreira identificada & Como a empresa lida \\
\hline Empresa A & $\begin{array}{l}\text { "As regulamentações e legislações não } \\
\text { beneficiam em nada na prática, sempre lançam } \\
\text { novas taxas e situações para proibirem a } \\
\text { produção dos produtos caso não atendam aos } \\
\text { requisitos". (entrevistado) }\end{array}$ & $\begin{array}{l}\text { Cumprindo-as, já que não há flexibilidade } \\
\text { "nem brechas". A empresa possui um } \\
\text { banco de dados para o cumprimento de } \\
\text { cada lei, na visão da empresa só existe } \\
\text { prejuízo, pois é necessário pagar taxas de } \\
\text { transporte para o produto poder entrar em } \\
\text { algum município e mesmo cumprindo deve } \\
\text { possuir a liberação ambiental. }\end{array}$ \\
\hline Empresa $B$ & $\begin{array}{l}\text { Quando não há possibilidade de serem } \\
\text { cumpridos. }\end{array}$ & $\begin{array}{l}\text { Cumprindo-as, já que não há flexibilidade } \\
\text { "nem brechas", a empresa possui acesso } \\
\text { a um site pago chamado Ambplan, o } \\
\text { qual faz o agendamento de tudo que deve } \\
\text { ser cumprido para cada lei. Na visão } \\
\text { da empresa, só existe prejuízo, pois é } \\
\text { necessário pagar altas taxas, por exemplo, } \\
\text { paga-se em torno de R\$ 200.000/ano em } \\
\text { análises laboratoriais terceirizadas de } \\
\text { tratamento de efluentes a montante e a } \\
\text { jusante, análise de solo, amostragem de } \\
\text { chaminés, análise de filtros que funcionam } \\
24 \text { horas, entre outros. A empresa faz } \\
\text { reuniões semanais para o monitoramento } \\
\text { de águas subterrâneas. }\end{array}$ \\
\hline Empresa $C$ & $\begin{array}{l}\text { Quando há a desmotivação para desenvolver } \\
\text { novos processos, por burocratizar o sistema, } \\
\text { "atrapalhando o andamento da empresa". Por } \\
\text { exemplo, para o transporte é exigido uma } \\
\text { licença e esta demora muito e, além disso, tudo } \\
\text { o que a empresa solicita, por exemplo, alguma } \\
\text { informação, os órgãos regulamentadores } \\
\text { demoram a atender. }\end{array}$ & $\begin{array}{l}\text { Cumprindo-as, já que não há flexibilidade } \\
\text { nem "brechas". A empresa possui acesso a } \\
\text { um site pago chamado Ambplan, o qual faz } \\
\text { o acompanhamento das legislações a serem } \\
\text { atendidas. }\end{array}$ \\
\hline Empresa D & $\begin{array}{l}\text { "O governo exige que as empresas estejam } \\
\text { sempre de acordo com suas legislações e } \\
\text { nunca proporcionou nenhum incentivo para } \\
\text { facilitar a empresa a alcançar tais objetivos". } \\
\text { (entrevistado) }\end{array}$ & Cumprindo com o que é exigido. \\
\hline Empresa $E$ & $\begin{array}{l}\text { Na prática, a empresa não enxerga puramente } \\
\text { a legislação como barreira, mas sim como uma } \\
\text { propaganda por cumprir tudo o que é exigido e } \\
\text { possuir certificações. }\end{array}$ & Cumprindo com o que é obrigatório. \\
\hline
\end{tabular}

Fonte: Coleta de dados (2013).

Quadro 9. Análise cruzada do fator "Consumidores".

\begin{tabular}{|c|c|c|}
\hline Consumidores & Barreira identificada & Como a empresa lida \\
\hline Empresa A & Não considera uma barreira. & - \\
\hline Empresa $B$ & $\begin{array}{l}\text { Quando não fazem a devolução da bateria após o } \\
\text { fim de sua vida útil. }\end{array}$ & $\begin{array}{l}\text { A empresa procura passar orientações } \\
\text { para o retorno das baterias no final de } \\
\text { sua vida útil e utiliza-se de estratégias de } \\
\text { vendas, garantindo a qualidade do produto. } \\
\text { Possuem um SAC para ouvi-los, buscando } \\
\text { sempre a melhoria do produto e corrigindo } \\
\text { determinadas falhas. Para isso contam com } \\
\text { o rastreamento de baterias. }\end{array}$ \\
\hline
\end{tabular}


Quadro 9. Continuação...

\begin{tabular}{|l|l|l|}
\hline Consumidores & \multicolumn{1}{|c|}{ Barreira identificada } & \multicolumn{1}{c|}{ Como a empresa lida } \\
\hline Empresa C & $\begin{array}{l}\text { Quando não fazem a devolução da bateria após } \\
\text { o fim de sua vida útil. A empresa acredita que } \\
\text { os clientes são os que mais prejudicam o meio } \\
\text { ambiente, pois pela falta de informação de } \\
\text { alguns deles acabam despejando o produto em } \\
\text { lugares inadequados. }\end{array}$ & $\begin{array}{l}\text { A empresa tem o apoio de uma terceirizada } \\
\text { que faz o recolhimento do "eletrolixo", } \\
\text { ou seja, lâmpadas fluorescentes e lixo } \\
\text { eletrônico. }\end{array}$ \\
\hline Empresa D & $\begin{array}{l}\text { "O cliente brasileiro olha ainda apenas o } \\
\text { preço e não possui o nível de conscientização } \\
\text { ambiental". (entrevistado) }\end{array}$ & $\begin{array}{l}\text { A empresa tenta conscientizar os clientes } \\
\text { sobre a devolução das baterias. }\end{array}$ \\
\hline Empresa E & $\begin{array}{l}\text { A não devolução e a conscientização dos } \\
\text { clientes finais. }\end{array}$ & $\begin{array}{l}\text { A empresa possui um programa de } \\
\text { treinamento para seus depositários para } \\
\text { facilitar a conscientização do recolhimento } \\
\text { da bateria usada. Espalham cartazes } \\
\text { informando sobre a importância desse ato } \\
\text { e que os clientes podem ganhar descontos } \\
\text { na troca. Quanto às concessionárias, a } \\
\text { empresa desenvolveu uma transportadora } \\
\text { própria para fazer o recolhimento das } \\
\text { baterias usadas. }\end{array}$ \\
\hline
\end{tabular}

Fonte: Coleta de dados (2013).

Quadro 10. Análise cruzada do fator "Concorrência".

\begin{tabular}{|c|c|c|}
\hline Concorrência & Barreira identificada & Como a empresa lida \\
\hline Empresa A & $\begin{array}{l}\text { Apesar de cada empresa atuar em um mercado distinto, } \\
\text { compete com produtores que não possuem a mesma } \\
\text { preocupação ambiental nos processos de produção e no } \\
\text { preço de venda. }\end{array}$ & $\begin{array}{l}\text { Atualmente a empresa não se } \\
\text { preocupa muito com essas empresas } \\
\text { "ilegais", pois prefere fazer produtos } \\
\text { de alta qualidade ambiental, } \\
\text { respeitando a legislação e atuando de } \\
\text { forma transparente e íntegra perante } \\
\text { o mercado. }\end{array}$ \\
\hline Empresa $B$ & $\begin{array}{l}\text { Quando a concorrência abaixa o preço e fica uma } \\
\text { diferença significativa da empresa B. }\end{array}$ & $\begin{array}{l}\text { A empresa elabora estratégias } \\
\text { (sigilosas e não expostas) para } \\
\text { recuperar seu espaço. }\end{array}$ \\
\hline Empresa $C$ & $\begin{array}{l}\text { "Quando a concorrência é desleal, por exemplo, as } \\
\text { baterias chinesas que possuem um preço menor que o } \\
\text { mercado e "enganam" o cliente, pois não possuem a } \\
\text { qualidade e nem o tratamento ambiental da empresa } \\
\text { C". (entrevistado) }\end{array}$ & $\begin{array}{l}\text { A empresa está sempre atualizada no } \\
\text { mercado e se mantendo competitiva. }\end{array}$ \\
\hline Empresa D & $\begin{array}{l}\text { Nem sempre tem o mesmo nível de atendimento às } \\
\text { legislações ambientais. }\end{array}$ & $\begin{array}{l}\text { A empresa procura adotar estratégias } \\
\text { que possam extinguir concorrentes } \\
\text { que não trabalham no padrão de } \\
\text { qualidade exigido pelos seus clientes. }\end{array}$ \\
\hline Empresa $E$ & $\begin{array}{l}\text { Localização geográfica, pois está fora do eixo } \\
\text { das regiões sul e sudeste. Altos custos para trazer } \\
\text { componentes e poder concorrer mais rapidamente. }\end{array}$ & $\begin{array}{l}\text { Conseguiu superar a barreira } \\
\text { da localização implantando um } \\
\text { transporte próprio de logística reversa } \\
\text { e lançou no mercado uma bateria } \\
\text { mais barata, embora com a mesma } \\
\text { qualidade das outras. }\end{array}$ \\
\hline
\end{tabular}

Fonte: Coleta de dados (2013).

contexto do setor automotivo, tendo similaridade de resultados com esta pesquisa.

Para 4 das 5 empresas, o fator "fornecedores" tende a ser uma barreira à adoção de práticas de
GSCM. Para as empresas A, B e C, os fornecedores podem intervir em suas iniciativas para GSCM quando elas não encontram fornecedores aptos a suprir adequadamente conforme requisitos 
ambientais. Ou seja, o fator "fornecedores" (Quadro 11) é uma barreira quando não atende aos requisitos de qualidade ambiental dos insumos desejados. As empresas estudadas estão buscando ações como desenvolver fornecedores e empregar a estratégia de dual sourcing.

Walker et al. (2008), Ferrer-Balas et al. (2008) e Mathiyazhagan et al. (2013) destacaram que "fornecedores" é uma barreira a ser muito bem trabalhada para melhorar as ações de GSCM. Nesta pesquisa, segundo as empresas pesquisadas, é importante que os fornecedores do setor de baterias automotivas busquem capacitação para melhorar os padrões de fornecimento de insumos com requisitos ambientais para estarem aptas a fornecerem para ele, pois, segundo Vanalle \& Santos (2014), as grandes montadoras do setor automotivo vão demandar de seus fornecedores a concretização da sustentabilidade em toda a cadeia de suprimentos.

Todas as 5 empresas foram unânimes ao considerar o fator "tecnologia" uma barreira à GSCM, quando o custo da mudança tecnológica é alto (Quadro 12). Apesar de o fator "tecnologia" ser uma potencial barreira, as empresas estudadas têm lidado com ele de forma a não prejudicar os investimentos em melhoria ambiental. As empresas A e B investem em tecnologias mínimas necessárias para manter um padrão ambiental adequado de seus processos. Já a empresa $\mathrm{C}$ busca por tecnologias que possibilitem que seus produtos reduzam o consumo de insumos. $\mathrm{E}$, as empresas D e E fazem pesquisas mercadológicas para avaliar possibilidade de atualização tecnológica. Portanto, o fator "tecnologia" se torna uma barreira quando o custo para acessá-la é muito alto, mas as empresas se preocupam em estar atualizadas tecnologicamente a ponto de não prejudicar a qualidade de seus produtos e colocar em risco os aspectos de segurança ambiental.

O referencial teórico pesquisado não apontou que o fator "tecnologia" seja algo preponderante para inibir ações de GSCM. Nesta pesquisa, pode-se afirmar o mesmo, pois as empresas se mantêm atualizadas tecnologicamente, apesar de um eventual custo de acessar novas tecnologias ambientais.

Das 5 empresas analisadas, 3 consideram o fator "sociedade e imagem corporativa" uma potencial barreira à adoção de práticas de GSCM (Quadro 13). Para as empresas B e C esse fator é uma potencial barreira, pois a manutenção da imagem ambiental alcançada nem sempre é algo trivial, em particular, para a empresa $\mathrm{C}$, pois, no passado, ela se envolveu em um acidente ambiental. Para essas empresas, a melhor maneira de lidar com esse fator é respeitando e atendendo aos requisitos legais e melhorando a qualidade ambiental de seus produtos.

Este fator não foi destacado no referencial teórico consultado e, nesta pesquisa, na perspectiva das empresas analisadas, também não por não ser um fator que tende a inibir ações em prol de GSCM.

Quadro 11. Análise cruzada do fator "Fornecedores".

\begin{tabular}{|c|c|c|}
\hline Fornecedores & Barreira identificada & Como a empresa lida \\
\hline Empresa A & $\begin{array}{l}\text { Quando os fornecedores não atendem ao que } \\
\text { a empresa deseja e a falta de um deles. }\end{array}$ & $\begin{array}{l}\text { A empresa trabalha em conjunto com seus } \\
\text { fornecedores para o cumprimento de suas } \\
\text { exigências e na melhoria da qualidade de seu } \\
\text { produto e possui uma carteira de fornecedores } \\
\text { qualificados. }\end{array}$ \\
\hline Empresa B & $\begin{array}{l}\text { Falta de fornecimento, único fornecedor e } \\
\text { monopólio. }\end{array}$ & $\begin{array}{l}\text { A empresa sempre busca pelo melhor custo/ } \\
\text { benefício em relação ao fornecedor e na falta } \\
\text { de um sempre busca por outros que atendam a } \\
\text { suas necessidades. }\end{array}$ \\
\hline Empresa $C$ & $\begin{array}{l}\text { Quando a empresa não encontra } \\
\text { fornecedores quando precisa e não são } \\
\text { ambientalmente corretos. "Há } 3 \text { anos era } \\
\text { quase impossível comprar de fornecedores } \\
\text { que atendessem às questões ambientais". } \\
\text { (entrevistado) }\end{array}$ & $\begin{array}{l}\text { A empresa sempre busca pelo melhor custo/ } \\
\text { benefício em relação ao fornecedor na } \\
\text { qualidade e questões ambientais. }\end{array}$ \\
\hline Empresa D & Não considera uma barreira. & - \\
\hline Empresa E & $\begin{array}{l}\text { Localização geográfica, por estar fora } \\
\text { do eixo da região sudeste; dificuldade de } \\
\text { importar componentes, principalmente o } \\
\text { chumbo puro. }\end{array}$ & $\begin{array}{l}\text { A empresa possui pelo menos } 3 \text { fornecedores } \\
\text { para cada área e, atualmente, está fazendo } \\
\text { um programa para trazer o máximo de } \\
\text { fornecedores para perto dela, acreditando que } \\
\text { isso melhorará o fornecimento, geração de } \\
\text { novos empregos e desenvolvimento da cidade, } \\
\text { além de reduzir seus custos. }\end{array}$ \\
\hline
\end{tabular}

Fonte: Coleta de dados (2013). 
Quadro 12. Análise cruzada do fator "Tecnologia".

\begin{tabular}{|l|l|l|}
\hline \multicolumn{1}{|c|}{ Tecnologia } & \multicolumn{1}{|c|}{ Barreira identificada } & \multicolumn{1}{c|}{ Como a empresa lida } \\
\hline Empresa $A$ & Alto custo de implantação. & $\begin{array}{l}\text { Apesar do alto custo, a empresa consegue } \\
\text { implantar o que é necessário, sobretudo quando } \\
\text { se refere às questões ambientais. }\end{array}$ \\
\hline Empresa $B$ & $\begin{array}{l}\text { Quando não consegue pagar tais tecnologias } \\
\text { e, às vezes, ter que manter um método } \\
\text { arcaico até conseguir um novo. }\end{array}$ & $\begin{array}{l}\text { Apesar dos desafios para implantar tecnologias } \\
\text { novas, a empresa consegue implantar o que } \\
\text { é necessário, sobretudo quando se refere às } \\
\text { questões ambientais. }\end{array}$ \\
\hline Empresa $C$ & Quando o custo da tecnologia é muito alto. \\
Empresa $D$ & O custo de implantação. & $\begin{array}{l}\text { A empresa investe em novas tecnologias para que } \\
\text { haja menor consumo de materiais e energia. }\end{array}$ \\
\hline Empresa $E$ & Custos de implantação. & $\begin{array}{l}\text { Por meio de estudos mercadológicos, a alta } \\
\text { gerência estuda o melhor custo-benefício para } \\
\text { implantar novas tecnologias. }\end{array}$ \\
\hline
\end{tabular}

Fonte: Coleta de dados (2013).

Quadro 13. Análise cruzada do fator "Sociedade e imagem corporativa".

\begin{tabular}{|c|c|c|}
\hline $\begin{array}{c}\text { Sociedade e Imagem } \\
\text { corporativa }\end{array}$ & Barreira identificada & Como a empresa lida \\
\hline Empresa A & Não considera uma barreira. & - \\
\hline Empresa $B$ & $\begin{array}{l}\text { Conseguir manter a imagem } \\
\text { adquirida. }\end{array}$ & $\begin{array}{l}\text { Respeitando as legislações, fazendo pesquisa de } \\
\text { mercado e desenvolvendo bons produtos. }\end{array}$ \\
\hline Empresa $C$ & $\begin{array}{l}\text { Alcançar e manter a imagem } \\
\text { adquirida; inclusive a empresa teve } \\
\text { sua imagem prejudicada em virtude } \\
\text { de um vazamento de substâncias } \\
\text { perigosas e a população rejeitou seus } \\
\text { produtos. }\end{array}$ & $\begin{array}{l}\text { Trabalhando para a melhoria da qualidade } \\
\text { ambiental da produção e ambiental e repassando } \\
\text { isso ao mercado e, assim, conseguindo melhorar } \\
\text { sua imagem e alavancar as vendas. }\end{array}$ \\
\hline Empresa D & Não considera uma barreira. & - \\
\hline Empresa $E$ & $\begin{array}{l}\text { Procura transformar barreiras em } \\
\text { pontos positivos para a empresa. }\end{array}$ & $\begin{array}{l}\text { A empresa luta para atingir suas metas e procura } \\
\text { fazer tudo da melhor forma. }\end{array}$ \\
\hline
\end{tabular}

Fonte: Coleta de dados (2013).

Considerando-se as formas como as empresas estudadas lidam com as barreiras externas, e considerando a homogeneidade entre as respostas, tem-se a percepção que os fatores "fornecedores" e "consumidores" são as barreiras de maior destaque nas empresas estudadas para adoção de práticas de GSCM. Isto se justifica, pois os consumidores têm sido uma barreira para a plena adoção da prática logística reversa nas empresas, uma vez que eles não necessariamente efetuam a devolução de baterias após o fim da vida útil; e a ausência de fornecedores preparados para suportar a mudança nos critérios ambientais do produto pode impedir a prática de compras verdes. Segundo o entrevistado da empresa C, "há 3 anos era quase impossível comprar de fornecedores que atendessem às questões ambientais".

Há outros fatores de barreiras externas que se destacaram na pesquisa como barreiras à GSCM, como "regulamentações e legislações governamentais" e "concorrência", mas esses fatores causam uma desmotivação à adoção de ações em prol de melhorias ambientais e não necessariamente são barreiras a serem superadas pelas empresas a fim de adotar práticas de GSCM, uma vez que as empresas estudadas têm seguido plenamente a legislação ambiental e não têm parado de investir em melhorias ambientais nos produtos e processos em função de certos concorrentes não terem a mesma preocupação ambiental que a deles.

Nesse sentido, pode-se afirmar que esta pesquisa vai ao encontro de alguns indicativos da literatura, como destacar que o fator "fornecedores" é uma barreira externa à adoção de práticas de GSCM (FERRER-BALAS et al., 2008; WALKER et al., 2008; MATHIYAZHAGAN et al., 2013). Por outro lado, apesar de os entrevistados terem comentado sobre os fatores "custos" e "regulamentações e legislações governamentais" como barreiras interna e externa, respectivamente, elas não são consideradas as mais críticas, uma vez que, na percepção dos entrevistados, custos é algo inerente ao negócio 
e atender à legislação é algo obrigatório e não há flexibilidade para lidar com elas. Portanto, não confirmando totalmente a hierarquia destacada na literatura pesquisada.
Com base nas barreiras identificas nas 5 principais empresas do setor, elencam-se oportunidades e desafios para à adoção de práticas de GSCM no setor de baterias automotivas do Brasil (Quadro 15).

Quadro 14. Características das 5 empresas estudadas.

\begin{tabular}{|c|c|c|c|c|c|}
\hline Característica & Empresa A & Empresa B & Empresa $C$ & Empresa D & Empresa $E$ \\
\hline Fundação & 1993 & 1965 & 1958 & 1931 (Brasil) & 1957 \\
\hline $\begin{array}{l}\text { Quantidade de } \\
\text { funcionários }\end{array}$ & 490 & 450 & 1400 & 1200 & 2000 \\
\hline $\begin{array}{l}\text { Principais } \\
\text { produtos }\end{array}$ & $\begin{array}{l}\text { Baterias } \\
\text { automotivas } \\
\text { Baterias } \\
\text { tracionárias } \\
\text { Baterias } \\
\text { estacionárias }\end{array}$ & $\begin{array}{l}\text { Baterias } \\
\text { automotivas }\end{array}$ & $\begin{array}{l}\text { Baterias } \\
\text { automotivas }\end{array}$ & $\begin{array}{l}\text { Baterias } \\
\text { automotivas } \\
\text { Baterias para } \\
\text { motos } \\
\text { Baterias } \\
\text { estacionárias }\end{array}$ & $\begin{array}{l}\text { Baterias } \\
\text { automotivas } \\
\text { Baterias } \\
\text { tracionárias } \\
\text { Baterias } \\
\text { estacionárias } \\
\text { Baterias para } \\
\text { motos }\end{array}$ \\
\hline $\begin{array}{l}\text { Mercado de } \\
\text { atuação }\end{array}$ & Reposição & Reposição & Reposição & $\begin{array}{l}\text { Reposição e } \\
\text { montadoras }\end{array}$ & $\begin{array}{l}\text { Reposição e } \\
\text { montadoras }\end{array}$ \\
\hline Origem do capital & Nacional & Nacional & Nacional & Multinacional & Nacional \\
\hline $\begin{array}{l}\text { Quantidade de } \\
\text { unidades }\end{array}$ & 2 & 1 & 1 & $\begin{array}{l}1 \text { Brasil e } 29 \text { no } \\
\text { mundo }\end{array}$ & $\begin{array}{l}3 \text { nacionais e } 1 \\
\text { internacional }\end{array}$ \\
\hline Certificações & $\begin{array}{l}\text { ISO } 9001(2000) \\
\text { ISO } 14001(2006) \\
\text { ISO TS } 16949 \\
\text { (indicada desde } \\
\text { 2010) } \\
\text { INMETRO } \\
\text { CPQD (Certificado } \\
\text { de Equipamentos e } \\
\text { Dispositivos) }\end{array}$ & $\begin{array}{l}\text { ISO 9001 } \\
\text { (2004) ISO } \\
14001 \text { (em } \\
\text { processo de } \\
\text { implantação) }\end{array}$ & $\begin{array}{l}\text { ISO 9001 } \\
\text { (2010) ISO } \\
14001 \text { (2012) } \\
\text { ISO TS } \\
16949 \text { (em } \\
\text { processo de } \\
\text { implantação) } \\
\text { IRAN AITA } \\
\text { (Argentina) }\end{array}$ & $\begin{array}{l}\text { ISO } 9001(1998) \\
\text { QS } 9000(1998) \\
\text { ISO } 9002(1995) \\
\text { ISO } 14001(2001) \\
\text { ISO TS } 16949 \\
(2001) \text { INMETRO }\end{array}$ & $\begin{array}{l}\text { ISO 9001 (1994) } \\
\text { ISO 14001 (2003) } \\
\text { ISO TS } 16949 \\
\text { Certificado D\&B } \\
\text { (2008) } \\
\text { Certificado Anatel } \\
\text { Certificado UMC } \\
\text { (1995) Q1 (1996 } \\
\text { e 2000) QSB } \\
\text { OHSAS 18001 } \\
\text { (em implantação) }\end{array}$ \\
\hline
\end{tabular}

Fonte: Elaborado pelos autores (2013).

Quadro 15. Oportunidades e desafios para o setor de baterias automotivas do Brasil.

\begin{tabular}{|c|c|}
\hline Oportunidades para setor & Desafios para o setor \\
\hline $\begin{array}{l}\text { - Criação de linhas de financiamento governamental } \\
\text { para reduzir o custo ao acesso a tecnologias } \\
\text { ambientais; } \\
\text { - Desenvolvimento de fornecedores para que eles } \\
\text { atendam a critérios técnicos e ambientais; } \\
\text { - Criação de cursos profissionalizantes e técnicos que } \\
\text { incluam procedimentos e condutas voltadas a gestão } \\
\text { de recursos naturais; } \\
\text { - Criação de cursos de curta duração pela Associação } \\
\text { do Setor para apoiar a capacitação das empresas no } \\
\text { cumprimento de requisitos legais; } \\
\text { - Criação de treinamentos e incentivos dentro da } \\
\text { empresa para os funcionários que mais colaborarem } \\
\text { com as metas ambientais da empresa; } \\
\text { - Valorização do investimento ambiental legal como } \\
\text { forma de marketing verde para melhorar a imagem } \\
\text { perante a sociedade. }\end{array}$ & $\begin{array}{l}\text { - Aumento da conscientização ambiental dos } \\
\text { clientes, para que eles devolvam a sucata } \\
\text { de baterias e reconheçam os investimentos } \\
\text { ambientais das empresas; } \\
\text { - Manutenção do preço competitivo e da alta } \\
\text { qualidade dos produtos sem comprometer os } \\
\text { aspectos ambientais; } \\
\text { - Suporte dos órgãos fiscalizadores para manter } \\
\text { o cenário competitivo do setor transparente e } \\
\text { equânime; } \\
\text { - Cumprimento pleno e correto das } \\
\text { regulamentações e legislações ambientais. }\end{array}$ \\
\hline
\end{tabular}

Fonte: Elaborado pelos autores (2013). 


\section{Conclusões}

Este trabalho possui o objetivo de apresentar e discutir como as principais empresas montadoras do setor de baterias automotivas instaladas no Brasil estão lidando com as barreiras à adoção de práticas de GSCM e, consequentemente, elencar as oportunidades e os desafios para o setor. Para atingi-los, foi conduzido um estudo de múltiplos casos com visitações in loco, entrevistas mediadas por um roteiro estruturado e análise de documentos disponibilizados pelas empresas.

As principais implicações desta pesquisa são:

- Esta pesquisa é pioneira no Brasil no que tange à temática "barreiras à adoção de práticas de GSCM";

- Os resultados apresentados e discutidos não são totalmente compatíveis com a literatura, provavelmente, em função das especificidades do setor. Por exemplo, este setor depende diretamente dos consumidores para a execução bem-sucedida da logística reversa e ele é intensivo em uso de mão de obra, fonte geradora de barreiras internas como "valores e fatores organizacionais" e "recursos humanos";

- Os fatores de destaque para as barreiras internas são "valores e fatores organizacionais" e "recursos humanas" e para as externas são "fornecedores" e "consumidores";

- Os resultados apresentados podem apoiar pequenas e médias empresas do setor de baterias automotivas a lidarem com as barreiras à adoção de práticas de GSCM, uma vez que trazem resultados provenientes das principais empresas do setor;

- Os resultados apresentados podem ajudar a fundamentar ações de políticas públicas, uma vez que destacam oportunidades e desafios para o setor.

Dentre as limitações relevantes, tem-se que apenas um profissional foi entrevistado por empresa e não foi adotada uma técnica mais robusta de análise de dados qualitativos, como a análise de conteúdo com suporte de um software. Além do mais, estudaram-se apenas empresas focais da cadeia de suprimentos, ao invés de estudar a cadeia estendida.

Como estudos futuros, sugerem-se a realização de uma survey para identificar a realidade do setor sobre esta temática, estudar empresas de pequeno e médio porte, e avançar a discussão deste tema em outros setores industriais, como o automotivo, um dos mais estudados no mundo.

\section{Referências}

ADRIANA, B. Environmental supply chain management in tourism: The case of large tour operators. Journal of Cleaner Production, v. 17, n. 16, p. 1385-1392, 2009. http://dx.doi.org/10.1016/j.jclepro.2009.06.010
AGERON, B.; GUNASEKARAN, A.; SPALANZANI, A. Sustainable supply management: an empirical study. International Journal of Production Economics, v. 140, n. 1, p. 168-182, 2012. http://dx.doi.org/10.1016/j. ijpe.2011.04.007

AZEVEDO, S. G.; CARVALHO, H.; CRUZ-MACHADO, V. The influence of green practices on supply chain performance: a case study approach. Transportation Research Part E, v. 47, n. 6, p. 850-871, 2011. http:// dx.doi.org/10.1016/j.tre.2011.05.017

BEAMON, B.M. Designing the green supply chain.Logistics Information Management, v. 12, n. 4, p. 332-342, 1999. http://dx.doi.org/10.1108/09576059910284159

BJORKLUND, M. Influence from the business environment on environmental purchasing: drivers and hinders of purchasing green transportation services. Journal of Purchaising \& Supply Management, v. 17, n. 1, p. 11-22, 2011. http://dx.doi.org/10.1016/j. pursup.2010.04.002

BRITO, R. P.; BERARDI, P. C. Vantagem competitiva na gestão sustentável da cadeia de suprimentos: um meta estudo. Revista de Administração de Empresas, v. 50, n. 2, p. 155-169, 2010. http://dx.doi.org/10.1590/ S0034-75902010000200003

CARTER, C. R.; CARTER, J. R. Interorganizational determinants of environmental purchasing: initial evidence from the consumer products industries. Decision Sciences, v. 29, n. 3, p. 659-684, 1998. http:// dx.doi.org/10.1111/j.1540-5915.1998.tb01358.x

CASTRO, B. H. R.; BARROS, D. C.; VEIGA, S. G. Baterias automotivas: panorama da indústria no Brasil, as novas tecnologias e como os veículos elétricos podem transformar o mercado global. BNDES Setorial, v. 37, p. 443-496, 2013.

CHIEN, M. K.; SHIH, L. H. An empirical study of implementation of green supply chain management practices in the electrical and electronic industry and their relation to organizational performances. International Journal of Environmental Science and Technology, v. 43, n. 3, p. 383-394, 2007.

CORBETT, C. J.; KLASSEN, R. D. Extending the horizons: environmental excellence as key to improving operations. Manufacturing and Service Operations Management, v. 8, n. 1, p. 5-22, 2006. http://dx.doi. org/10.1287/msom.1060.0095

DIAS, S. L. F. G.; LABEGALINI, L.; CSILLAG, J. M. Sustentabilidade e cadeia de suprimentos: uma perspectiva comparada de publicações nacionais e internacionais. Revista Produção, v. 22, n. 3, p. 517-533, 2012. http://dx.doi.org/10.1590/ S0103-65132012005000034

DÜES, C. M.; TAN, K. H.; LIM, M. Green as the new Lean: how to use lean practices as a catalyst to greening your supply chain. Journal of Cleaner Production, 2012. No prelo.

FERRER-BALAS, D. et al. An international comparative analysis of sustainability transformation across seven universities. International Journal of Sustainability in Higher Education, v. 9, n. 3, p. 295-316, 2008. http:// dx.doi.org/10.1108/14676370810885907 
FORTES, J. Green supply chain management: a literature review. Otago Management Graduate Review, v. 7, n. 1, p. 51-62, 2009.

GIUNIPERO, L. C.; HOOKER, R. E.; DENSLOW, D. Purchasing and supply management sustainability: drivers and barriers. Journal of Purchasing \& Supply Management, v. 18, n. 4, p. 258-269, 2012. http:// dx.doi.org/10.1016/j.pursup.2012.06.003

GOVINDAN, K.; CHENG, T. C. E. Environmental supply chain management. Resources, Conservation and Recycling, v. 55, n. 6, p. 557-558, 2011. http://dx.doi. org/10.1016/j.resconrec.2011.04.006

HERVANI, A. A.; HELMS, M. M.; SARKIS, J. Performance measurement for green supply chain management. Benchmarking: An Internaltional Journal, v. 12, n. 4, p. 330-353, 2005.

LEE, S. Y. Drivers for the participation of small and medium-sized suppliers in green supply chain initiatives. Supply Chain Management an International Journal, v. 13, n. 3, p. 185-198, 2008. http://dx.doi. org/10.1108/13598540810871235

LEWIS, H.; GRETSAKIS, J. Design + environmental: a global guide to designing greener goals. Sheffield: Greenleaf Publishing, 2001.

LIU, X. et al. Case studies of green supply chain management in China. International Journal of Economics and Management Engineering, v. 1, n. 1, p. 22-34, 2011.

LUTHRA, S. et al. Barriers to implement green supply chain management in automobile industry using interpretive structural modeling technique: an Indian perspective. Journal of Industrial Engineering and Management, v. 4, n. 2, p. 231 257, 2011.

MATHIYAZHAGAN, K. et al. An ISM approach for the barrier analysis in implementing green supply chain management. Journal of Cleaner Production, v. 47, p. 283-297, 2013. http://dx.doi.org/10.1016/j. jclepro.2012.10.042

MIN, H.; GALLE, W. P. Green purchasing practices of US firms. International Journal of Operations \& Production Management, v. 21, n. 9, p. 1222-1238, 2001. http:// dx.doi.org/10.1108/EUM0000000005923

MUDGAL, R. K. et al. Modeling the barriers of green supply chain practices: an Indian perspective. International Journal of Logistics Systems and Management, v. 7, n. 1, p. 81-107, 2010.

MUDULI, K. et al. Barriers to green supply chain management in Indian mining industries: a graph theoretic approach. Journal of Cleaner Production, v. 47, p. 335-344, 2013. http://dx.doi.org/10.1016/j. jclepro.2012.10.030

PAJUNEN, N. et al. Drivers and barriers of effective industrial material use. Minerals Engineering, v. 29, p. 39-46, 2012. http://dx.doi.org/10.1016/j. mineng.2011.12.008

PEREIRA, G. M. C. et al. Sustentabilidade socioambiental: um estudo bibliométrico da evolução do conceito na área de gestão de operações. Produção, v. 21, n. 4, p. 610-619, 2011. http://dx.doi.org/10.1590/ S0103-65132011005000053
PERRON, G. M. Barriers to environmental performance improvements in Canadian SMEs. Canadá: Dalhousie University, 2005.

PREUSS, L. In dirty chains? Purchasing and greener manufacturing. Journal of Business Ethics, v. 34, n. 3, p. 345-359, 2001. http://dx.doi. org/10.1023/A:1012549318786

SARKIS, J. Manufacturing strategy and environmental consciousness. Technovation, v. 15, n. 2, p. 79-97, 1995. http://dx.doi.org/10.1016/0166-4972(95)96612-W

SARKIS, J. Evaluating environmentally conscious business practices. European Journal of Operational Research, v. 107, n. 1, p. 159-174, 1998. http://dx.doi. org/10.1016/S0377-2217(97)00160-4

SARKIS, J. Manufacturing's role in corporate environmental sustainability: concerns for the new millennium. International Journal of Operations \& Production Management, v. 21, n. 5-6, p. 666-85, 2001. http://dx.doi.org/10.1108/01443570110390390

SARKIS, J.; ZHU, Q.; LAI, K. An organizational theoretic review of green supply chain management literature. International Journal of Production Economics, v. 130, n. 1, p. 1-15, 2011. http://dx.doi.org/10.1016/j. ijpe. 2010.11 .010

SCOPUS. (2013).Scopus Recuperado em julho de 2013, de http://www.scopus.com/results/results.url?sort=plf$\mathrm{f} \& \mathrm{src}=\mathrm{s} \& \mathrm{st} 1=\% 22$ green + supply + chain + management $\% 22+$ and+\%22barriers $\% 22 \&$ sid=E410F9F3718081F 4F49F536031D551A0.ZmAySxCHIBxxTXbnsoe5w $\% 3 a 30 \&$ sot $=b \& s d t=b \& s l=61 \& s=$ TITLE-ABS-KEY\% $28 \% 22$ green+supply+chain+management $\% 22+$ and $+\%$ 22barriers \%22\%29\&origin=searchbasic\&editSaveSear $\mathrm{ch}=\& \mathrm{txGid}=\mathrm{E} 410 \mathrm{~F} 9 \mathrm{~F} 3718081 \mathrm{~F} 4 \mathrm{~F} 49 \mathrm{~F} 536031 \mathrm{D} 551 \mathrm{~A} 0$. ZmAySxCHIBxxTXbnsoe5w\%3a3.

SIMPSON, D. Institutional pressure and waste reduction: the role of investments in waste reduction resources. International Journal of Production Economics, v. 139, p. 330-339, 2012. http://dx.doi.org/10.1016/j. ijpe.2012.05.020

SRIVASTAVA, S. K. Green supply-chain management: a state-of-the-art literature review. International Journal of Management Reviews, v. 9, n. 1, p. 53-80, 2007. http://dx.doi.org/10.1111/j.1468-2370.2007.00202.x

THUN, J.; MULLER, A. An empirical analysis of green supply chain management in the German automotive industry. Business Strategy and the Environment, v. 19, p. 119-132, 2010.

TSOULFAS, G. T.; PAPPIS, C. P. A model for supply chains environmental performance analysis and decision making. Journal of Cleaner Production, v. 16, p. 1647-1657, 2008. http://dx.doi.org/10.1016/j. jclepro.2008.04.018

VANALLE, R. M.; SANTOS, L. B. Análise das práticas de sustentabilidade utilizadas na gestão da cadeia de suprimentos: pesquisa de campo no setor automotivo brasileiro. Gestão \& Produção, v. 21, n. 2, p. 323-339, 2014. http://dx.doi.org/10.1590/0104-530X47613

WALKER, H.; SISTO, L.; MCBAIN, D. Drivers and barriers to environmental supply chain management practices from the public and private sector. Journal 
of Publishing \& Supply Chain Management, v. 14, n. 1, p. 69-85, 2008.

WALTON, S.; HANDFIELD, R.; MELNYK, S. The green supply chain: integrating suppliers into environmental management processes. International Journal of Puchasing and Materials Management, v. 34, n. 2, p. 2-11, 1998.

WOLFSLEHNER, B.; VACIK, H. Evaluating sustainable forest management strategies with the analytic network process in a pressure-state-response framework. Journal of Environmental Management, v. 88, p. 1-10, 2008. PMid:17418934. http://dx.doi.org/10.1016/j. jenvman.2007.01.027

YONGAN, Z.; MENGHAN, L. Research on Green Supply Chain Design for Automotive Industry Based on Green SCOR Model. In: International Conference on Information Management, Innovation Management and Industrial Engineering, 2011, Shenzhen.

ZHANG, B.; BI, J.; LIU, B. Drivers and barriers to engage enterprises in environmental management initiatives in Suzhou Industrial Park, China. Frontiers of Environmental Science \& Engineering in China, v. 3, n. 2, p. 210-220, 2009. http://dx.doi.org/10.1007/ s11783-009-0014-7

ZHU, Q. H.; SARKIS, J. An inter-sectorial comparison of green supply chain management in China: drivers and practices. Journal of Cleaner Production, v. 14, p. 472-486, 2006. http://dx.doi.org/10.1016/j. jclepro.2005.01.003

ZHU, Q. et al. Firm-level correlates of emergent green supply chain management practices in the Chinese context. Omega, v. 36, n. 36, p. 577 591, 2008a.

ZHU, Q. et al. The role of organizational size in the adoption of green supply chain management practices in China. Corporate Social Responsibility and Environmental Management, v. 15, n. 6, p. 322-337, 2008b. http://dx.doi.org/10.1002/csr.173

ZHU, Q. H.; SARKIS, J.; LAI, K .H. Green supply chain management implications for closing the loop. Transportation Research Part E: Logistics and Transportation Review, v. 44, n. 1, p. 1-18, 2008 c. http://dx.doi.org/10.1016/j.tre.2006.06.003

ZHU, Q. H.; SARKIS, J.; LAI, K. H. Confirmation of a measurement model for green supply chain management practices implementation. International Journal of Production Economics, v. 111, n. 2, p. 261-73, 2008d. http://dx.doi.org/10.1016/j. ijpe.2006.11.029

ZHU, Q.; GENG, Y. Drivers and barriers of extended supply chain practices for energy saving and emission reduction among Chinese manufacturers. Journal of Cleaner Production, v. 40, p. 6-12, 2013. http://dx.doi. org/10.1016/j.jclepro.2010.09.017 